\title{
Information and informed consent in a longitudinal screening involving children: a questionnaire survey
}

\author{
Ulrica Gustafsson Stolt ${ }^{\star, 1}$, Gert Helgesson ${ }^{2}$, Per-Erik Liss ${ }^{3}$, Tommy Svensson ${ }^{4}$ and \\ Johnny Ludvigsson ${ }^{1}$
}

${ }^{1}$ Department of Molecular and Clinical Medicine, Division of Paediatrics, Faculty of Health Sciences, SE-581 85 Linköping, Sweden; ${ }^{2}$ Centre for Bioethics at Karolinska Institutet \& Uppsala University, Uppsala Science Park, SE-751 85 Uppsala, Sweden; ${ }^{3}$ Department of Health and Society, Linköping University, SE-581 83 Linköping, Sweden; ${ }^{4}$ Department of Behavioural Sciences, Linköping University, SE-581 83 Linköping, Sweden

This empirical study explores participants' perceptions of information and understanding of their children's and their own involvement in a longitudinal screening, the ABIS Study. ABIS (All Babies In Southeast Sweden) is a multicentre, longitudinal research screening for Type 1 diabetes and multifactorial diseases involving 17005 children and their families. For this study, a random selection of mothers was made, using perinatal questionnaire serial numbers from the ABIS study. In total, 293 of these mothers completed an anonymous questionnaire (response rate $73.3 \%$ ). Our findings from the questionnaire indicate a marked difference between the reported satisfaction with and understanding of the information provided on the one hand and the significant lack of knowledge of some of the aims and methods of the $A B I S$ screening on the other, namely concerning high-risk identification of involved children, potential prevention and future questionnaires. Two questions evoked by our results are: (1) what information is required for participants in longitudinal studies involving children? and (2) how do we ensure and sustain understanding, and thus in a prolonging, informed consent in these studies? This study underlines the importance of an increased understanding of the ethical issues that longitudinal research on children raise and the need to discuss how information and informed consent strategies should be analysed and designed in longitudinal studies.

European Journal of Human Genetics (2005) 13, 376-383. doi:10.1038/sj.ejhg.5201336

Published online 15 December 2004

Keywords: longitudinal studies; informed consent; empirical ethics; children; research ethics

\section{Introduction}

As a result of increased understanding of the interplay between genetic and environmental factors affecting the development of multifactorial diseases - such as Type 1 diabetes (IDDM) and cancer - longitudinal screening trials are now subject to increased attention,

${ }^{*}$ Correspondence: $\operatorname{Dr} U$ Gustafsson Stolt, Faculty of Health Sciences, Department of Molecular and Clinical Medicine, Division of Paediatrics, Linköping SE-581 85, Sweden. Tel: +46 13 221335; Fax: + 4613 184265; E-mail: ulrgu@imk.liu.se

Received 2 March 2004; revised 5 October 2004; accepted 8 October 2004 mainly from the clinical field. Clearly, there are enormous economic values at stake, both for individuals and society as a whole, if diabetes and other multifactorial diseases can be successfully prevented or delayed. The last decade has therefore seen a number of studies initiated in order to 'map' children in the general population and their first years of life. Two examples in northern Europe of such large-scale longitudinal studies are ALSPAC (Avon Longitudinal Study of Parents and Children) in the Bristol area of the United Kingdom and the ABIS study (All Babies In Southeast Sweden) in southern Sweden. ${ }^{1-4}$ 
However, screening and interventions, especially when involving young children, raise a number of ethical concerns. Genetic testing or screening of presymptomatic 'healthy' children, where there is no acknowledged medical intervention or accepted preventive measure is complicated due to ethical and potentially psychosocial problems. $^{5-9}$ Therefore, it is important that screening and intervention is performed according to accepted ethical standards: informed consent must be obtained, appropriate care should be taken to minimise risks, the right to integrity and confidentiality must be respected and safeguarded, etc. ${ }^{10-13}$

Longitudinal screening involving children generates specific problems. Such screening usually involves interventions at certain 'check-points' during a time-span of several years, which generates both practical and ethical concerns. First of all, it involves long-term contact with a large number of participating children and families. If commenced during pregnancy or birth, it will most likely involve contact with a large number of persons employed at a variety of wards, children welfare centres, and even schools (if continued in time). Depending on profession and place of work, the staff involved will most likely have different responsibilities, depending on the design of the screening. For example, a midwife working at the maternity welfare will perhaps have as primary responsibility to inform prospective participating families and obtain consent, while a nurse at a children welfare centre might be expected to answer questions, obtain biological data, etc. Longitudinal screening also involves a large number of researchers working within their different medical fields. In addition, it handles a substantial amount of data, both biological and written, and most of which will be stored and analysed in computers. Methods for safeguarding stored information need special attention since they are important means to protect the integrity and confidentiality of the participants, and also important for the public trust.

Longitudinal studies of this sort initially involve competent adults and incompetent minors. However, the children grow up during the course of the research project and should at some point be informed about the study that their parents consented to let them participate in. One specific question concerns the children's right to autonomy and integrity: participating children should, at some stage, have the right to form their own opinion regarding their participation and decide either to continue taking part in the project or withdraw their parents' proxy consent. The decisions these children make can have a direct effect on the study at hand: if some of them decide to withdraw from the study, there will be less data to analyse; if many of them withdraw, then the quality of the study will be threatened.

Another concern is the data and results generated by the study. In a longitudinal screening, results of different sorts will be produced over the course of a long time: for example, predictive indicators, data concerning the existence of autoimmune reactions, results regarding risk factors generated from environmental data, etc. One difficult question related to this concerns ownership and access to data. For example, for how long are parents in their full right to access data or results concerning their child?

Several of these issues are not unique to longitudinal studies, and the discussion about how to promote and protect the interests of children involved in research is, and has been, intense. ${ }^{14-19}$ There is also a growing consensus that this discussion would benefit from complementary empirical data. ${ }^{9,20-23}$

In this paper, we present empirical data from a longitudinal screening involving children. Since several of the questions raised regarding longitudinal studies may be related to information and informed consent, this empirical study attempts to improve our understanding of how participants perceive information, the informed consent process and the aims and methods of the ongoing ABIS study.

\section{Research setting: the ABIS study}

ABIS is designed as a longitudinal and geographically located research screening for Type 1 diabetes and multifactorial diseases such as allergies, cancer, rheumatism and celiac disease. The cohort sample of this multicentre study is comprised of all births $(n=21700)$ in a 2-year period (October 1997-October 1999) in the southeast region of Sweden. In all, $78.6 \%$ gave their consent to participate, resulting in 17005 participants. The primary aims are to identify and acquire knowledge about the environmental factors that in combination with genetic factors cause the immunological processes leading to the development of Type 1 diabetes and other immune-mediated diseases. The study also aims at identifying high-risk children and a potential secondary prevention of Type 1, if knowledge and methods to do so are attained.

The first samples for the ABIS study were taken at the delivery ward when the children were born - blood for genetic studies and serum for studies of virus antibodies. Later, breast milk and hair were taken at maternity wards, where also vein samples were taken from 3000 mothers and fathers. The first in a series of questionnaires were to be filled in, comprising of 118 questions concerning, for example, infections during pregnancy, living conditions, diet, medicines, smoking habits and exposures. When mother and child went home they were provided with a diary in which infections, medicines, vaccinations, life events and nutrition (breast-feeding and introduction of gluten, soya and cow milk protein) was to be noted. The 12-month control included biological samples and a second questionnaire containing complementary questions about food habits, parental feelings, stress, etc. 
Table 1 Factors related to information and informed consent

\begin{tabular}{|c|c|c|c|c|}
\hline Respondents $(n=293)$ & (n) & $\%(n)(1-2)$ & $\%(n)(3-4)$ & $\%(n)(5-6)$ \\
\hline $\begin{array}{l}\text { (i) General project information (aims, methods, participation, results) } \\
\text { (ii) Information concerning samples (blood, hair, breast milk etc.) }\end{array}$ & $\begin{array}{l}(n=293) \\
(n=293)\end{array}$ & $\begin{array}{l}\text { Satisfactory } \\
77.1(226) \\
76.8(225)\end{array}$ & $\begin{array}{l}19.5(57) \\
19.8(58)\end{array}$ & $\begin{array}{c}\text { Not satisfactory } \\
3.4(10) \\
3.4(10)\end{array}$ \\
\hline $\begin{array}{l}\text { (iii) Information concerning questionnaire(s) } \\
\text { (iv) Information concerning diary }\end{array}$ & $\begin{array}{l}(n=293) \\
(n=292)\end{array}$ & $\begin{array}{l}74.7(219) \\
61.3(179)\end{array}$ & $\begin{array}{l}19.8(58) \\
29.4(86)\end{array}$ & $\begin{array}{l}5.5(16) \\
9.3(27)\end{array}$ \\
\hline $\begin{array}{l}\text { (v) Information sufficient for decision to participate? } \\
\text { (vi) Information understood? } \\
\text { (vii) A fully voluntary decision? }\end{array}$ & $\begin{array}{l}(n=291) \\
(n=287) \\
(n=291)\end{array}$ & $\begin{array}{c}\text { Yes, absolutely } \\
85.6(249) \\
68.3(196) \\
96.2(280)\end{array}$ & $\begin{array}{r}10.6(31) \\
29.3(84) \\
3.5(10)\end{array}$ & $\begin{array}{c}\text { No, not at all } \\
3.8(11) \\
2.4(7) \\
0.3(1)\end{array}$ \\
\hline
\end{tabular}

At present the 2.5-3-year control has resulted in over 10000 questionnaires and approximately 40000 biological samples (blood, urine, faeces etc). The 5-6-year control has commenced, so far resulting in 3500 questionnaires.

The initial studies included GAD 65 and IA-2 determination, HLA-typing (positivity for DQ8, DQ2 and DQ6 in all children), and subsequent correlation to environmental factors. The children and families with a potential high risk of developing type 1 diabetes have been asked to give their consent to take part in follow-up studies (the international TRIGR study and the PRODIA study).

\section{The ABIS informed consent process}

All pregnant women in the region were informed during their visits to the maternity welfare centre. In accordance with the project design, they received oral, written and audiovisual information (video and posters designed for information purposes) on two occasions: at 12 and 25-29 weeks of pregnancy. The oral and written information contained information about the aims and methods presented above. Time and opportunity to ask questions was offered on both occasions. Due to concern for respect of personal integrity, the respondents were asked to discuss the decision with their partners before labour. The formal decision was then made at delivery and noted in their medical record. Additional information was given both at time of delivery and at maternity wards.

\section{Research design and methods}

In this study, the 400 respondents were randomly selected from the perinatal questionnaire serial numbers of those women who had given birth during 1999, in order to avoid a possible duration effect, that is, that those recruited first had forgotten information about the study. The questionnaire was distributed together with an information letter clearly indicating that this research ethical study was independent from the main ABIS study and in no way affected their participation in the main study. Furthermore, we asked the respondents to answer the questionnaire anonymously. After being informed and asked to give their consent, 293 women completed the survey, resulting in a response rate of $73.3 \%$ after one reminder. We designed the questionnaire partly on the basis of the findings from previous qualitative interview studies with participating and nonparticipating mothers and staff involved in the initial information and consent process. ${ }^{4}$ For the data presentation in Table 1, we transformed the Likert-type scales into three-level scales (1-2, 3-4, 5-6). Ethical approval was obtained from the regional Research Ethics Committee.

\section{Study population}

There are no indications that this study population differs from the larger unselected cohort, even though we should be aware that the respondents belong to the $78.6 \%$ of the cohort consenting to participate in the ABIS screening project. Earlier studies within the ABIS Research Group have showed that the total number of 17005 participants is highly representative of the general population with regard to social situation (family status, educational level and ethnic background). ${ }^{3}$ Furthermore, we found no significant differences between responders and nonresponders in relation to age, family status, parity or education. Nor did we find any significant differences when comparing our respondents with the larger ABIS-study population. ${ }^{3}$ An analysis was made concerning potential correlates of knowledge and understanding (age, education). However, no significant differences were found.

\section{Results}

Approximately $89 \%$ of the respondents report being satisfied with the general ABIS information concerning aims, methods, etc (participants marking 1-3 of the sixgrade scale). A similar proportion satisfaction was reported regarding information on more specific details, such as the biological samples, the initial questionnaire and the 1-year diary. A majority of the respondents $(93 \% ; n=272)$ regarded the information they received as sufficient for their decision to participate. Approximately $90 \%$ indicate that they understood the information they received. Only $2.4 \%$ of the respondents report not having 
fully understood the information they received. In addition, more than 95\% answered that they had made a voluntary decision to participate.

Based on earlier empirical indications we asked the respondents to reflect upon the information they had received and their corresponding understanding with regard to the main aims and methods of the ABIS study, including facts regarding their participation. Important to notice is that all statements we asked them to respond to were true.

The results of the analysis (Table 2) indicate that a number of participants are either unaware of or cannot recall, at the time of completing the questionnaire, some of the primary aims and methods of the ABIS study. Approximately $31 \%$ of the participants disagree to or state that they are unsure of the ABIS basic aim of high-risk identification. Almost 55\% of the respondents do not agree to a potential contact in case of their child being identified as belonging to the high-risk group (see Research setting: the ABIS study). Regarding the methods and general research design, only $38.1 \%$ indicate that they are aware of or can recall that they were to be contacted to fill out questionnaires when their children were $2.5-3$ years and again at 5-6 years of age.

The question presented in Table 3 was intended primarily as a basic crosscheck question. The respondents were asked to mark the statement closest to their own opinion, considering the information they had received and what perceptions/knowledge they had about the ABIS study. The result of the analysis shows that approximately $40 \%$ of the participants seem to be of the opinion, at least at the time of completing the questionnaire, that the ABIS research and results will primarily benefit future children and generations, thus with no anticipated potential benefit or therapeutic use for themselves and their own child.
Although not statistically significant, Table 4 presents the correlation between reported satisfaction with/understanding of the information provided and answers about knowledge of different aims and methods of the ABIS study. The table presents the respondents who marked 1-3 of the six grades Likert-scale with regard to both their attitudes towards the information provided (89.1\% being satisfied) and their understanding of it (90.2\%). When compared to the respondents' own perceptions of the information received and their current understanding of the different aims and methods of the ABIS study, a difference can be seen. Of those regarding the information provided clearly satisfactory for their decision to participate in the study, there is a high degree of disagreement or unsureness of some of the basic aims and methods such as high-risk identification and later intermediate questionnaires. With the respondents marking the $1-2$ of the Likert scale a similar trend can be seen: $32 \%$ does not agree with high-risk identification; $53 \%$ disagree with or are unsure of a possible future contact and $73 \%$ of those respondents

Table 3 Factors related to understanding and knowledge II

$$
\begin{aligned}
& \text { Respondents ( } n=293) \\
& \text { Perception of future results and potential findings } \\
& \text { of the ABIS study? } \\
& \text { (1) I am of the opinion that aims and results can } \\
& \text { have a direct use for my own child, together } \\
& \text { with other participating children } \\
& \text { (2) I am of the opinion that aims and results will } \\
& \text { only be of help to future children and } \\
& \text { generations }
\end{aligned}
$$$$
\%(n)
$$

Perception of future results and potential findings $\quad(n=290)$

(3) I have no specific opinion

Table 2 Factors related to understanding and knowledge I

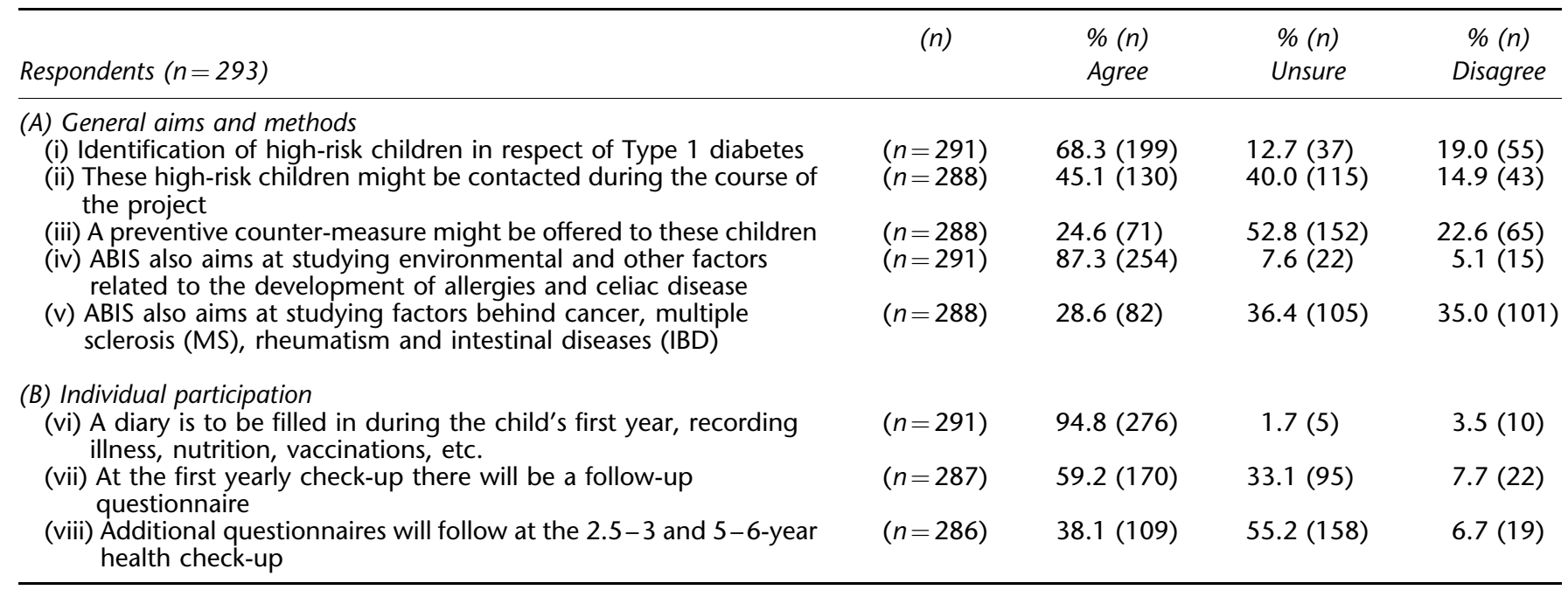


Table 4 Correlation between satisfaction/understanding and knowledge/comprehension (Participants marking 1-3 of six grades Likert-scale)

\begin{tabular}{lcr}
\hline Participants stating being & $\begin{array}{c}\text { Satisfied with information } \\
(n=261,89.1 \%)\end{array}$ & $\begin{array}{c}\text { Understanding the } \\
\text { information ( } n=259,90.2 \%)\end{array}$ \\
\hline Disagreeing with or being unsure about the claims below & $\%$ & $\%$ \\
(i) Identification of high-risk children in respect of Type 1 diabetes & 31.4 & 27.0 \\
(ii) Potential contact in case of high-risk identification & 74.8 & 48.9 \\
(iii) A potential prevention in case of high risk & 11.9 & 67.5 \\
(iv) A study of factors related to allergies and celiac disease & 69.3 & 11.3 \\
(v) A study of factors related to cancer, multiple sclerosis (MS), & & 65.1 \\
rheumatism and intestinal diseases (IBD) & 5.0 \\
(vi) Diary during child's first 12 months & 39.0 & 3.9 \\
(vii) Follow-up questionnaire at age 12 months & 51.7 & 34.5 \\
(viii) Additional questionnaires at 2.5-3 and 5-6-year health check-up & 48.2 \\
\hline
\end{tabular}

seem unsure or unaware of the potential prevention. Thus, it seems clear that the high degree of unsureness or disagreement visible is not limited to those also reporting a 'less' satisfaction, as otherwise possible to suspect. When compared with the data presented in Table 4, it furthermore appears that the degree of agreement with the actual aims of the stuffy is the same whatever the degree of 'satisfaction with information'.

Furthermore, it seems clear that there are a substantial number of participants who state having understood the information but who nevertheless disagreed with, or were unsure of several of the true statements they were asked to respond to. Also here the trend remains with the respondents marking 1-2, that is, indicating they 'clearly' understood the information: $38.3 \%$ deny or cannot recall the high-risk identification; $67.5 \%$ are unaware of or cannot recall the potential contact and $93 \%$ seem unsure of or unaware of a possible prevention. Interesting to note is that it appears to be the subjects stating they understood the information who are more prone to disagree with or are unsure of the basic aims.

\section{Discussion}

In summary, this study presents empirical data generated from an ongoing longitudinal research screening involving children and their parents, where the families will be actively followed during the first 6 years of the children's lives and most likely longer. The study suggests that a majority of the respondents are satisfied with the information provided and regard it as sufficient for their consent to participate in the ABIS study. They also regard themselves as having understood the information. On the other hand, we found a significant proportion of the respondents who are either unsure of or disagree with several of what may be called basic aims and methods of the ABIS screening. Most noticeable are the findings regarding lack of knowledge about high-risk identification of the involved children
(31.7\%), the potential contact with these families (54.9\%), possible prevention/intervention (75.4\%) and future intermediate questionnaires (61.9\%). Furthermore, we found that this 'lack of knowledge' is not limited to the respondents who report being less satisfied and having understood less, as Table 4 demonstrates. It appears even that the degree of agreement with for example, the aims of the study seem to be the same whatever the degree of 'satisfaction of information', and also that subjects stating they understood the information seem to be generally more prone to disagree or be unsure of the aims. This certainly deserves attention and a future more in-depth discussion. What may be argued, however, is that these results indicate the difficulties in sustaining understanding of a study continuing over time, and also show the difficulties in judging whether participants have a true understanding of a study through merely the participants' own opinions.

What then, are reasonable explanations for these results?

First, it should be noted that we get very different figures if we base them only on those participants who disagree with the statements and exclude those who are unsure. However, the most relevant results are those that include both categories since they together make up the group of participants who fail to recall information they have received. Part of the discrepancy may simply be explained by failures to remember information received at the onset of the study. Another possibility is that parents in fact made a distinction between the primary aims of the ABIS study (mapping of genetic and environmental factors; high-risk identification) being more immediate and achievable and the secondary ones of prevention and intervention. A number of participants may thus have disregarded the secondary aims completely. Some may find some aspects of the study less relevant to their consent to participate than others do. Their decisions to participate may even have been made in a way that deviates from the assumption of rational choice that underlies our reasoning 
(and the standard views of informed consent). Also, their initial decision to take part in the ABIS project may, for instance, have been made as an act of altruism, once they felt convinced that the project was backed up by reputable institutions and professionals.

Finally, there may also be different standards among the participants of what constitutes 'sufficient' understanding. To explicitly describe what sufficient understanding actually mean is however a somewhat difficult task. Ethical codes and guidelines usually list some important aspects of the study that the subject should be informed about - like aims, methods, anticipated benefits and potential risks but nothing substantial that can guide us concerning the interpretation of the term. ${ }^{1}$ In their well-known work Principles of Biomedical Ethics, Beauchamp and Childress discuss understanding in two contexts: autonomous action and, more specifically, informed consent. ${ }^{2}$ They state that for an action to be autonomous it needs 'a substantial degree' of understanding and freedom from constraint, 'not a full understanding or a complete absence of influence' ${ }^{16}$ The key issue here is what a 'substantial degree' is. What constitutes relevant beliefs may vary with the situation undoubtedly, there is a difference between giving informed consent to a clinical standard intervention (for example a minor surgery) and consenting both for oneself and one's child to participate in a longitudinal preventive screening. ${ }^{24,25}$

In general, understanding in order to make wellinformed decisions in order to, for example, participate in medical research seem to be problematic: international studies point to the need for a continuous discussion on how to best enable (potential) research subjects to make informed decisions. Lack of understanding among participants has been faced on several occasions: a number of

\footnotetext{
$\overline{1 \text { (for example, World Medical Association (1964) Declaration of }}$ Helsinki. Ethical Principles for Medical Research Involving Human Subjects; The Belmont report (1979) Office of the Secretary. Ethical Principles and Guidelines for the Protection of Human Subjects of Research; International Ethical Guidelines for Biomedical Research Involving Human Subjects (1982). Prepared by the Council for International Organisations of Medical Sciences (CIOMS) and WHO; Recommendation No. R (90) 3 Concerning Medical Research on Human Beings. Council of Europe, Committee of Ministers. The Nüremberg Code, the Declaration of Helsinki, and the CIOMS code of 1982 (1993) also emphasise the need, even duty, to ensure that the research subjects have understood the information.)

${ }^{2}$ (Informed consent is here understood in the following way: When someone (A) has given (B) his or her consent to an intervention-trial $(\mathrm{T})$, the following conditions have been met: (1) B has asked A about participation in $\mathrm{T}$; (2) B has given adequate information about $\mathrm{T}$ and about B's participation in $\mathrm{T}$; (3) A was a competent person; (4) A sufficiently understood the conditions of participating in T; (5) A consented to participate in T; (6) A's consent was made voluntarily; (7) A notified B of his/ her consent to participate in $\mathrm{T}$ (authorisation).
}

empirical studies reveal difficulties regarding the comprehension of clinical trials, for example, therapeutic misunderstandings, inadequate information and unawareness of options and potential risks and benefits. ${ }^{26-29}$

However, we believe the observations made in this empirical study may aid in broadening the discussion about information, consent and understanding by raising some important questions relating to large-scale longitudinal studies involving children:

- What information is necessary when participating in longitudinal studies that may last many years?

- How do we ensure understanding and informed consent in longitudinal studies involving children and how do we sustain the consent once given?

The first question concerns information. Should information to participants in longitudinal studies be different from the information given to potential participants in, for example, a short-term clinical trial? The answer must be 'no' in the sense that the basic information needed for satisfactory informed consents should not be any different. However, longitudinal studies involving children and their families also have long-term aspects that need special attention. First of all, the research involves small and growing children. When research involves children (for example, ABIS, the ALSPAC (Avon Longitudinal Study of Parents and Children in UK, the ongoing TRIGR and PRODIA studies, etc), we also have to take into account the need to promote and protect the interests of the children involved in such research. ${ }^{8,19,30}$ Generally, the involvement of children in research is continuously debated and it is often argued that risk assessments and methods to secure valid consents from participating families are essential in securing ethically sound research on children., ${ }^{71,12}$ The trend is to add more weight to children's decision-making capacity and growing autonomy, which is also emphasised in international guidelines of later date. ${ }^{31-33}$

Since our findings, for example, show the difficulties in promoting understanding of such long-term aspects as potential future prevention (if high-risk children are identified), we believe there is a need to discuss how and when such information should be given in longitudinal studies, and also how to promote the best possible understanding over time, initially to the families and later to the children. Information regarding possible future contact and prevention may be regarded as mere 'potential aims', or 'secondary aims' and thus not as important as the primary and more achievable. From another point it may be regarded as absolutely essential to provide, being information that may influence the decision made on behalf of their children, both initially when asked for the first consent (ie to participate in a study) but also at later date when either repeated information is given or a renewed consent is asked for (for example, the invitation 
to a follow-up study). Such information may as well influence the future decision made by the children themselves. One question that our findings thus raise concern whether or not such possibilities of prevention or future therapeutic use should be an obligatory part of the original research information provided to participating families and thus also be understood at least to some extent for their consents to be sufficiently informed. And furthermore, to what extent (and for how long time?) should such information be at least partly, mirrored in the participants understanding?

The second question concerns how we should ensure understanding and informed consent in longitudinal studies involving children and sustain the consent once given? We argue that much of the theoretical attention has so far been focused upon what we may call 'preconsent' information. ${ }^{13-16,28,29}$ However, in longitudinal studies a different approach to information and informed consent may be more appropriate. Our empirical data indicate the need to discuss whether repeated information should be provided during the course of long-term studies. The data presented in this paper generates from participants having been involved in the ABIS study for less than 1.5 year. Pilot data from 2500 respondents participating in the ongoing 5-6-year control questionnaire clearly support these findings: $80 \%$ report having sufficient knowledge of the ABIS study for continued participation. At the same time, while $83 \%$ acknowledge the aim being to identify high-risk children in the birth cohort, more than half of the respondents were unaware of or unsure of that they could be individually contacted (which some families with a genetic predisposal have been, for example, to participate in the TRIGR study).

From an ethical point of view the participating families should benefit from repeated information: it would potentially increase their awareness and chances to exercise autonomy, promote the rights of participating children and sustain the initial informed consent. From a clinical point of view, this may have a positive impact on levels of participation and ultimately on the effectiveness of research programmes. Yet another issue tied to longitudinal studies involving children is how to handle information and consent in relation to these children: when should they be informed and how? And when should they have a say about their participation?

In conclusion, this study underlines the importance of an increased understanding of ethical issues, particularly concerning information and informed consent, in longitudinal screening programmes. Out of respect for participants' autonomy and personal integrity (children as well as adults), it must be ensured that they can make well-informed decisions regarding their participation in longitudinal research. In this context empirical studies may provide valuable data. ${ }^{20,34}$ This study also suggests the importance of discussing how strategies of information and informed consent can be analysed and designed in longitudinal studies. As we most likely will see more of longitudinal research correlating genetic status with long-term environmental factors, there will be a growing need for special ethical considerations, not only for the protection of participants' autonomy and integrity, but also because the public confidence in the commitment of researchers to the welfare of child subjects and respect for the rights of parents need to be upheld and promoted.

\section{Acknowledgements}

We would like to thank all the families who participated in this research. We are grateful to the ABIS nurses and Ann-Christine Gilmore-Ellis for their support during the research process. This study was financially supported by the JDF-Wallenberg Foundation (Grant K98-99JD-12813-01A), the Soderbergs Foundation and the Swedish Child Diabetes Foundation (Svenska Barndiabetesfonden). Ethical approval for the study was obtained from the regional research ethical committee at Linköping University.

\section{References}

1 Golding J: European Longitudinal Study of Pregnancy and Childhood (ELSPAC). Paediatr Perinatal Epidemiol 1989; 3: 460-469.

2 Golding J, the ALSPAC Study Team: Children of the nineties: a resource for assessing the magnitude of long-term effects of prenatal and perinatal events. Cont Rev Obstetr Gynaecol 1996; 8: 89-92.

3 Ludvigsson J, Ludvigsson M, Sepa A: Screening for pre-diabetes in the general child population may be reassuring. Pediatr Diabetes 2001; 2: 170-174.

4 Gustafsson Stolt U, Liss P-E, Svensson T, Ludvigsson J: Attitudes to bioethical issues: a case study of a screening project. Soc Sci Med 2002; 54: 1333-1344.

5 Harper PS, Clarke A: Should we test children for 'adult' genetic diseases? Lancet 1990; 335: 1205-1206.

6 Clarke A: Introduction. The genetic testing of children. Oxford: Bios Scientific Publishers, 1998.

7 Chadwick R, Shickle D, ten Have H (eds): The ethics of genetic screening. Dordrecht: Kluwer Academic Publishers, 1999.

8 Marteau TM, Richards MPM (eds): The troubled helix: social and psychological implications of the new human genetics. Cambridge: Cambridge University Press, 1996.

9 Michie S, Marteau TM: Predictive genetic testing in children: the need for psychological research. Br J Health Psychol 1996; 1: 3-14.

10 Chadwick RF, Thompson AK (eds): Genetic information. Acquisition, access, and control. New York: Kluwer Academic/Plenum Publishers, 1999.

11 Harper PS, Clarke AJ: Genetics, society and clinical practice. Oxford: BIOS Scientific Publishers, 1997.

12 American Society of Human Genetics: Points to consider: ethical, legal, and psychological implications of genetic testing in children and adolescents. Am J Hum Gen 1995; 57: 1233-1241.

13 Emanuel EJ, Wendler D, Grady C: What makes clinical research ethical? JAMA 2000; 283: 2701-2711.

14 Chadwick R, Levitt M, Shickle D (eds): The right to know and the right not to know. Avebury: Aldershot, 1997.

15 Reilly PR, Boshar MF, Holtzman SH: Ethical issues in genetic research: disclosure and informed consent. Nat Genet 1997; 15: $16-20$.

16 Beauchamp TL, Childress JF: Principles of biomedical ethics, 5th edn. New York: Oxford University Press, 2001. 
17 Knoppers B, Avard D, Cardinal G, Cranley Glass K: Children and incompetent adults in genetic research: consent and safeguards. Nat Rev 2002; 3: 221-224.

18 Ross LF: Predictive genetic testing for conditions that present in childhood. Kennedy Inst Ethics J 2002; 12: 225-244.

19 Ross LF, Moon M: Ethical issues in genetic testing of children; in Beauchamp T, Walters L (eds): Contemporary issues in bioethics, 6th edn: Wadsworth: Thomson Learning, 2003.

20 Hope T: Empirical medical ethics. J Med Ethics 1999; 25: 219-222.

21 Michie S, Bobrow M, Marteau TM, on behalf of the FAP Collaborative Research Group: Predictive genetic testing in children and adults: a study of emotional impact. J Med Genet 2001; 38: 519-526.

22 Marteau TM, Lerman C: Genetic risk and behavioural charge. BMJ 2001; 332: 1056-1059.

23 Goodenough T, Williamson E, Kent J, Ashcrot R: What did you think about that? Researching Children's perceptions of participation in a longitudinal genetic epidemiological study. Children Soc 2002; 17: 113-125.

24 O'Neill O: Some limits of informed consent. J Med Ethics 2003; 29: $4-7$.

25 Knoppers BM, Avard D, Cardinal G et al: Children and incompetent adults in genetic research: consent and safeguards. Nature 3: 221-224.
26 Giardiello FM, Brensinger MS, Petersen GM et al: The use and interpretation of commercial APC gene testing for familial adenomatous polyposis. N Engl J Med 1997; 336: 823-827.

27 Joffe S, Cook EF, Cleary PD, Clark JW, Weeks JC: Quality of informed consent: a new measure of understanding among research subjects. J Natl Cancer Inst 2001; 93: 139-146.

28 Moreno J, Caplan AL, Wolpe PR, the members of the project on informed consent, Human Research Ethics Group: Updating protections for human subjects involved in research. JAMA 1998; 280: $1951-1958$.

29 Beskow LM, Burke W, Merz JF et al: Informed consent for population-based research involving genetics. JAMA 2001; 286: $2315-2321$.

30 Doyal L, Tobias J (eds): Informed consent in medical research. London: BMJ Books, 2000.

31 [8]Alderson P: Young Children's Rights. London: Jessica Kingsley, 2000.

32 European Convention on the Exercise of Children's Rights. Strasbourg, 1996.

33 International Symposium 'Bioethics and the Rights of the Child'. Considerations on Bioethics and the Right of the Child, Monaco,: 2000.

34 Bjorn E, Rossel P, Holm S: Can the written information to research subjects be improved? An empirical study. J Med Ethics 1999; 25: 263-267. 